\title{
Mitochondrial Respiration of Adipocytes Differentiating From Human Mesenchymal Stem Cells Derived From Adipose Tissue
}

\author{
I. KLADNICKÁ ${ }^{1,2}$, M. ČEDÍKOVÁ ${ }^{3,4}$, M. KRIPNEROVÁ ${ }^{5}$, J. DVOŘÁKOVÁ ${ }^{6}$, \\ M. KOHOUTOVÁ ${ }^{3,4}$, Z. TŮMA ${ }^{4}$, D. MÜLLEROVÁ ${ }^{1,2}$, J. KUNCOVÁ ${ }^{3,4}$
}

${ }^{1}$ Department of Public Health and Preventive Medicine, Faculty of Medicine in Pilsen, Charles University, Pilsen, Czech Republic, ${ }^{2}$ NTIS, European Center of Excellence New Technologies for the Information Society, University of West Bohemia, Pilsen, Czech Republic, ${ }^{3}$ Institute of Physiology, Faculty of Medicine in Pilsen, Charles University, Pilsen, Czech Republic, ${ }^{4}$ Biomedical Center, Faculty of Medicine in Pilsen, Charles University, Pilsen, Czech Republic, ${ }^{5}$ Institute of Biology, Faculty of Medicine in Pilsen, Charles University, Pilsen, Czech Republic, ${ }^{6}$ Institute of Medical Chemistry and Biochemistry, Faculty of Medicine in Pilsen, Charles University, Pilsen, Czech Republic

Received March 21, 2019

Accepted October 4, 2019

\section{Summary}

Burden of obesity is increasing in the contemporary world. Although multifactorial in origin, appropriate mitochondrial function of adipocytes emerges as a factor essential for healthy adipocyte differentiation and adipose tissue function. Our study aimed to evaluate mitochondrial functions of human adiposederived mesenchymal stem cells committed to adipogenesis. On days $0,4,10$, and 21 of adipogenesis, we have characterized adipocyte proliferation and viability, quantified lipid accumulation in maturing cells, performed qualitative and quantitative analysis of mitochondria, determined mitochondrial respiration of cells using high-resolution respirometry, and evaluated mitochondrial membrane potential. In the course of adipogenesis, mitochondrial oxygen consumption progressively increased in states ROUTINE and E (capacity of the electron transfer system). State LEAK remained constant during first days of adipogenesis and then increased probably reflecting uncoupling ability of maturing adipocytes. Citrate synthase activity and volume of mitochondrial networks increased during differentiation, particularly between days 10 and 21 . In addition, lipid accumulation remained low until day 10 and then significantly increased. In conclusion, during first days of adipogenesis, increased mitochondrial respiration is needed for transition of differentiating cells from glycolytic to oxidative metabolism and clonal expansion of preadipocytes and then more energy is needed to acquire typical metabolic phenotype of mature adipocyte.
\end{abstract}

\section{Key words}

Mesenchymal stem cells • Adipocyte • Adipogenesis • Highresolution respirometry $\bullet$ Mitochondria

\section{Corresponding author}

J. Kuncová, Institute of Physiology, Faculty of Medicine in Pilsen, Charles University, Alej Svobody 76, 32300 Pilsen, Czech Republic. E-mail: jitka.kuncova@lfp.cuni.cz

\section{Introduction}

Obesity represents an increasing problem of the contemporary world. It leads to various chronic morbidities like Type 2 diabetes mellitus, hypertension, atherosclerosis, heart disease, stroke, cancer, infertility etc. (Cai et al. 2010, Castro et al. 2014, Luna-Luna et al. 2015, Mission et al. 2015, Zimmet et al. 2001). Caloric intake exceeding energy expenditure produces a metabolic state that promotes hypertrophy and hyperplasia of adipocytes (Shepherd et al. 1993). It is supposed that the increase in adipocyte number is triggered by signaling factors that induce the commitment of pluripotent mesenchymal stem cells residing in the vascular stroma to the adipocyte lineage. When committed, preadipocytes are subjected to mitotic clonal expansion undergoing two or three cell divisions and then they gradually acquire typical adipocyte metabolic and 
morphological characteristic in the process of differentiation (Tang and Lane 2012). All three stages are essential for the development of obesity and they are tightly linked to the increased energy intake over long time periods (Qiao et al. 2019, Shepherd et al. 1993, Spiegelman and Flier 1996).

Appropriate function of white adipose tissue is dependent on energy provided by mitochondria (Kusminski and Scherer 2012). It has been also suggested that adipocyte differentiation is at least partly driven by mitochondrial oxidative phosphorylation (Luz et al. 2019, Zhang et al. 2013).

To study adipogenesis in vitro, 3T3-L1 preadipocyte cell line originally derived as a subclone of the 3T3 mouse embryonic fibroblast cell line is widely used in experimental practice and some data are also available on mitochondrial respiration of these cells (Morrison and McGee 2015). However, the translation potential of the experimental results acquired from these cells has been challenged by several important issues (Sadie-Van Gijsen 2019).

Human cell models include various types of stem cells that are able to differentiate into adipocytes, namely adipose tissue derived mesenchymal stem cells that allow investigation of all phases of adipocyte formation. Despite concerns expressed by some investigators (Berry et al. 2014), these cells represent a more relevant model suitable for research in adipocyte biology than most rodent cell lines (Sadie-Van Gijsen 2019).

The aim of our study was to extend earlier observations of other researchers in the field of mitochondrial physiology of differentiating human adipocytes. We have used human adipose-derived mesenchymal stem cells committed to adipogenesis and on days $0,4,10$ and 21 of differentiation, we have characterized their proliferation and viability, quantified lipid accumulation in maturing cells, performed qualitative and quantitative analysis of mitochondria, determined mitochondrial respiration of cells using highresolution respirometry, and evaluated mitochondrial membrane potential.

\section{Methods}

\section{Cell culture and differentiation}

Human adipose-derived mesenchymal stem cells (hADMSCs), isolated from a female donor from subcutaneous adipose tissue and characterized by flow cytometry were purchased from Thermo Fisher (Thermo
Fisher Scientific, Carlsbad, CA, USA) and cultivated as described previously (Mullerova et al. 2017). Briefly, the cells were seeded at $1 \times 10^{5}$ cells and cultured in Petri dishes (TPP Techno Plastic Products, Trasadingen, Switzerland) in commercially available culture medium MesenPRO RSTM Medium supplemented with MesenPRO RSTM Growth Supplement with reduced serum level (2\%), $1 \%$ L-glutamine and $1 \%$ gentamicin (all Thermo Fisher Scientific, Carlsbad, CA, USA).

After $80 \%$ confluence was reached, the hADMSCs were cultured for adipogenic differentiation in culture plates according to the manufacturer's instructions in StemPro ${ }^{\circledR}$ Adipogenesis Differentiation Basal Medium (DM) with StemPro ${ }^{\circledR}$ Adipogenesis Supplement and 1\% gentamicin (all Thermo Fisher Scientific, Carlsbad, CA, USA). The medium was changed every 3 days up to a total incubation time of 21 days. The cells were maintained and cultured into differentiated adipocytes under $5 \% \mathrm{CO}_{2}$ atmosphere at $37^{\circ} \mathrm{C}$.

\section{Cell proliferation}

Human adipose-derived stem cells were seeded at 5000 per well on the bottom of 96 dark well plate and treated as described above. Samples were labeled on days 0, 4, 10, 21 using NucBlue ${ }^{\circledR}$ Live ReadyProbes ${ }^{\circledR}$ Reagent (Thermo Fisher Scientific, Carlsbad, CA, USA). All samples were scanned using the Olympus IX83 (Olympus, Tokyo, Japan) equipped with a VisiScope Live Cell Imagine system at $100 \times$ magnification. The images were analyzed using the ImageJ (FIJI) software.

\section{Cell viability}

PrestoBlue $^{\mathrm{TM}}$ cell viability reagent (Thermo Fisher Scientific, Carlsbad, CA, USA) was used to evaluate the viability and proliferation of cells (Dejmek et al. 2019). The reagent uses mitochondrial activity to reduce the non-fluorescent blue resazurin to the fluorescent pink resofurin. PrestoBlue ${ }^{\mathrm{TM}}$ reagent $(10 \mu \mathrm{l})$ was added to $90 \mu \mathrm{l}$ medium with cells on 96 dark well plate. Cells were incubated for $10 \mathrm{~min}$ at $37^{\circ} \mathrm{C}$. The bottom-read fluorescence was read at $560 \mathrm{~nm}$ (excitation) and $590 \mathrm{~nm}$ (emission) by Synergy $^{\mathrm{TM}}$ HT microplate reader (BioTek, Winooski, VT, USA).

\section{Differentiation and maturation of adipocytes}

\section{Oil Red O staining}

Human adipose-derived stem cells were stained using Oil Red $\mathrm{O}$ solution which stains intracellular 
triglyceride droplets. Medium was removed from each well, cells were twice rinsed in phosphate buffered saline (PBS) and fixed in $4 \%$ formaldehyde prepared in PBS for $1 \mathrm{~h}$ at room temperature. Then the cells were washed twice in distilled water and stained in Oil Red O solution. This solution was prepared dissolving $0.5 \mathrm{~g}$ of Oil Red O powder (Sigma-Aldrich, Prague, Czech Republic) in $100 \mathrm{ml}$ of isopropanol (Sigma-Aldrich, Prague, Czech Republic), filtered with absorbent paper and blended in the ratio $3: 2$ - three parts of $0.5 \%$ Oil Red O solution and two parts of distilled water. The cells were incubated for 15 min with the Oil Red O solution at room temperature, twice washed in distilled water to remove unbound dye and the cells were then visualized using an inverted microscope Olympus CX41 (Olympus, Tokyo, Japan) connected to a digital camera.

\section{Quantification of lipid accumulation}

Lipid accumulation was measured by Oil Red O extraction by lysis and gentle agitation $10 \mathrm{~min}$ at room temperature. We used $4 \%$ NP-40 (Sigma-Aldrich, Prague, Czech Republic) in $100 \%$ isopropanol as a lysis buffer. The extract $(100 \mu \mathrm{l})$ was transferred into a 96 well plate. The absorbance was measured at $490 \mathrm{~nm}$ using a plate reader Synergy HT (BioTek, Winooski, VT, USA).

\section{Indirect immunofluorescence}

Cells were washed in PBS, fixed for $60 \mathrm{~min}$ in $4 \%$ formaldehyde with PBS at room temperature, and permeabilized in PBS containing $0.3 \%$ Triton X-100 for 15 min followed by blocking in PBS with $1 \%$ bovine serum albumin (BSA) and $10 \%$ normal donkey serum at room temperature for $60 \mathrm{~min}$. After blocking, the cells were incubated with antibody against fatty acid binding protein 4 (FABP4; R\&D Systems, Minneapolis, MN, USA) in working solution (PBS containing $0.03 \%$ Triton $\mathrm{X}-100,1 \% \mathrm{BSA}, 10 \%$ normal donkey serum and antiFABP4 in final concentration $10 \mu \mathrm{g} / \mathrm{ml}$ ) overnight at $2-8{ }^{\circ} \mathrm{C}$. After three 5 -min rinsing in PBS with $1 \%$ BSA, cells were incubated for $1 \mathrm{~h}$ in donkey anti-goat IgG NorthernLights ${ }^{\mathrm{TM}}$ NL557-conjugated secondary antibody (R\&D Systems, Minneapolis, MN, USA) diluted 1:200 in 1\% BSA in PBS in the dark for $60 \mathrm{~min}$ at room temperature. The coverslips were washed, placed on microscope slides with a mounting medium (ProLong Gold Antifade Mountant with DAPI, Molecular Probes, Eugene, OR, USA) and visualized with a fluorescence microscope Olympus CX41 (Olympus, Tokyo, Japan) connected to a digital camera.
Qualitative and quantitative analysis of mitochondria

\section{Fluorescent probe staining}

Fluorescent probes, MitoTracker ${ }^{\mathrm{TM}}$ Red CMXRos and NucBlue ${ }^{\circledR}$ Live ReadyProbes ${ }^{\circledR}$ Reagent (both Molecular Probes, Eugene, OR, USA) were used to visualize mitochondria and nucleus. To label mitochondria, cells were incubated with MitoTracker ${ }^{\mathrm{TM}}$, which passively diffuses across the plasma membrane and accumulates in active mitochondria. Cell-permeant nuclear counterstain NucBlue ${ }^{\circledR}$ Live ReadyProbes ${ }^{\circledR}$ Reagent containing Hoechst ${ }^{\circledR} 33342$ dye (2'-[4ethoxyphenyl]-5-[4-methyl-1-piperazinyl]-2,5'-bi-1Hbenzimidazole) emits blue fluorescence when bound to DNA with an emission maximum at $460 \mathrm{~nm}$. It is detected through a blue/cyan filter.

Culture medium was replaced with Live Cell Imaging Solution (Molecular Probes, Eugene, OR, USA). Two drops of NucBlue ${ }^{\circledR}$ Live ReadyProbes ${ }^{\circledR}$ Reagent were added per milliliter of medium and MitoTracker ${ }^{\mathrm{TM}}$ was added in the final concentration $100 \mathrm{nM}$. Cells were incubated in the dark for $30 \mathrm{~min}$ and then visualized by the Hamamatsu Orca-ER camera mounted on the Olympus IX 81 inverted microscope at 200× magnification (Olympus, Tokyo, Japan).

\section{High-resolution respirometry}

Oxygen consumption by adipocytes was evaluated on days $0(n=6), 4(n=17)$ and $21(n=18)$ of differentiation. To measure mitochondrial respiration of intact cells, oxygraph Oroboros O2k (Oroboros, Innsbruck, Austria) connected to the computer with DatLab software for data acquisition and analysis (Oroboros, Innsbruck, Austria) was used. The oxygen flux was calculated as a negative time derivative of the oxygen concentration in $2 \mathrm{ml}$ glass chambers at $37^{\circ} \mathrm{C}$ (Pesta and Gnaiger 2012).

StemPro ${ }^{\circledR}$ Adipogenesis Differentiation medium was stirred at $350 \mathrm{rpm}$ and equilibrated with air for $60 \mathrm{~min}$. After closing the chambers, the samples of intact adipocytes were injected into the chambers using Hamilton ${ }^{\circledR}$ syringe and respiratory activity of intact cells was assessed as routine respiration (ROUT; R). Then, non-phosphorylating LEAK state (L; oxygen consumption needed for electron transport compensating for proton leak across the inner mitochondrial membrane) was induced by addition of oligomycin $(2.5 \mu \mathrm{mol} / \mathrm{l})$, an ATP-synthase inhibitor. Maximum capacity of the electron transfer system (state E), was reached by titration of uncoupler trifluorocarbonylcyanide phenylhydrazone 
(FCCP; $0.05 \mu \mathrm{mol} / 1$ titration steps). Oxygen consumption was then inhibited by inhibitor of complex III antimycin A $(2.5 \mu \mathrm{mol} / \mathrm{l})$ to achieve residual oxygen consumption (ROX). The cells were counted using Bürker's hemocytometer (average cell count was $\sim 4 \times 10^{5}$ cells per chamber) and oxygen consumption was expressed in pmol $\mathrm{O}_{2} /\left(\mathrm{s} .10^{6}\right.$ cells $)$ and corrected to $\mathrm{ROX}$ and instrumental background. The used protocol is shown in Figure 4A.

\section{Citrate synthase activity}

Determination of citrate synthase activity was used to estimate mitochondrial content in the samples from each oxygraph chamber. Two hundred microliters of the mixed and homogenized chamber content were added to $800 \mu \mathrm{l}$ of the assay medium containing $0.1 \mathrm{mmol} / 1$ 5,5-dithio-bis-(2-nitrobenzoic) acid, $0.25 \%$ Triton-X, $0.5 \mathrm{mmol} / 1$ oxaloacetate, $0.31 \mathrm{mmol} / \mathrm{l}$ acetyl coenzyme A, $5 \mu \mathrm{mol} / 1$ EDTA, $5 \mathrm{mmol} / 1$ triethanolamine hydrochloride, and $0.1 \mathrm{~mol} / 1 \quad$ Tris-HCl, $\quad \mathrm{pH} 8.1$ (Kuznetsov et al. 2002). The enzyme activity was measured spectrophotometrically at $412 \mathrm{~nm}$ and $30^{\circ} \mathrm{C}$ over $200 \mathrm{~s}$ and expressed in mIU per $10^{6}$ cells

\section{Mitochondrial membrane potential}

The mitochondrial membrane potential was measured using the JC-1 Mitochondrial Membrane Potential Assay Kit (Mitosciences, Abcam, Cambridge, UK). The cells were seeded at $1 \times 10^{4}$ cells on a dark well plate and cultured as explained earlier. The mitochondrial membrane potential was evaluated on days $0 \quad(n=12)$, $4(n=12), 10(n=12)$ and $21(n=12)$ of differentiation. The cells were washed once with $\mathrm{PBS}$ and incubated with JC-1 dye $(1 \mu \mathrm{M})$ at $37^{\circ} \mathrm{C}$ for $10 \mathrm{~min}$. Then the cells were rinsed twice and were analyzed on a fluorescence spectrophotometer (Synergy HT, BioTek, Winooski, VT, USA) at excitation $475 \mathrm{~nm}$ and emission 530/590 nm. In addition, the changes in mitochondrial membrane potential were also analyzed by flow cytometer (FACSCanto II; BD Biosciences, San Jose, CA, USA). JC-1 solution $(10 \mu \mathrm{l}$ at the concentration of $200 \mu \mathrm{M})$ was added to cell suspension $(1 \mathrm{ml})$ and cells were incubated at $37^{\circ} \mathrm{C}$ for $25 \mathrm{~min}$. Washing with $\mathrm{PBS}$ and centrifugation (1500 rpm; $5 \mathrm{~min}$ ) followed the incubation period. The supernatant was removed; the pellet was resuspended in $500 \mu \mathrm{l}$ PBS and immediately measured on the flow cytometer. The red/green fluorescence intensity ratio was determined to evaluate mitochondrial membrane potential.

\section{Data analysis and statistics}

Statistical analysis was performed using OriginPro 2017 software (OriginLab Corporation, Northampton, MA, USA). After testing for normality of distribution, data were compared using one-way ANOVA with Tukey's post hoc test. Values of $\mathrm{p}<0.05$ were considered significant.

\section{Results}

\section{Cell culture and differentiation}

Human adipose-derived stem cells (hADMSCs) were maintained and cultured into differentiated adipocytes under standard conditions for 21 days. Cells harvested on day 0 were mesenchymal stem cells with typical fibroblastic spindle shape with several spurs and large nucleus. During adipogenic differentiation, cell morphology has changed - the cells gradually increased in volume, small fat vacuoles began to appear and then gradually increased in size (Fig. 1A-D). The phenotype of mature adipocytes was confirmed by the presence of FABP4 protein.

\section{Cell proliferation and viability}

As shown in Figure 2, a trend to increase the cell number was observed just after induction of differentiation (day 0 vs. day 4, p=0.05004) and it became significant thereafter (day 0 vs. day $10, \mathrm{p}=0.006$; day 0 vs. day $21, \mathrm{p}<0.0001)$. In the later course of adipogenesis, mitotic division has slowed down (day 10 vs. day $21, p>0.05$ ). This corresponds to our other results, where lipid accumulation is observed instead of mitotic division in the second phase of differentiation.

Cell viability determined by PrestoBlue ${ }^{\mathrm{TM}}$ reagent was expressed in fluorescent units (FU). No statistically significant changes in cell viability were observed during differentiation (Fig. 3).

\section{Quantification of lipid accumulation}

Oil Red $\mathrm{O}$ solution has been used to stain adipocytes and to visualize fat droplets. Oil Red O interacts with lipids to give a red-orange colored product. During differentiation, an insignificant increase in the fat content of the cells was observed and then, between days 10 and 21, fat accumulation significantly increased which corresponded to the increasing amount of measured Oil Red $\mathrm{O}$ staining (Figs 1A-D and 3C). The data are in accord with our previous finding that at this time, no significant mitotic division is taking place, but rather acquiring mature adipocyte-specific metabolic phenotype. 

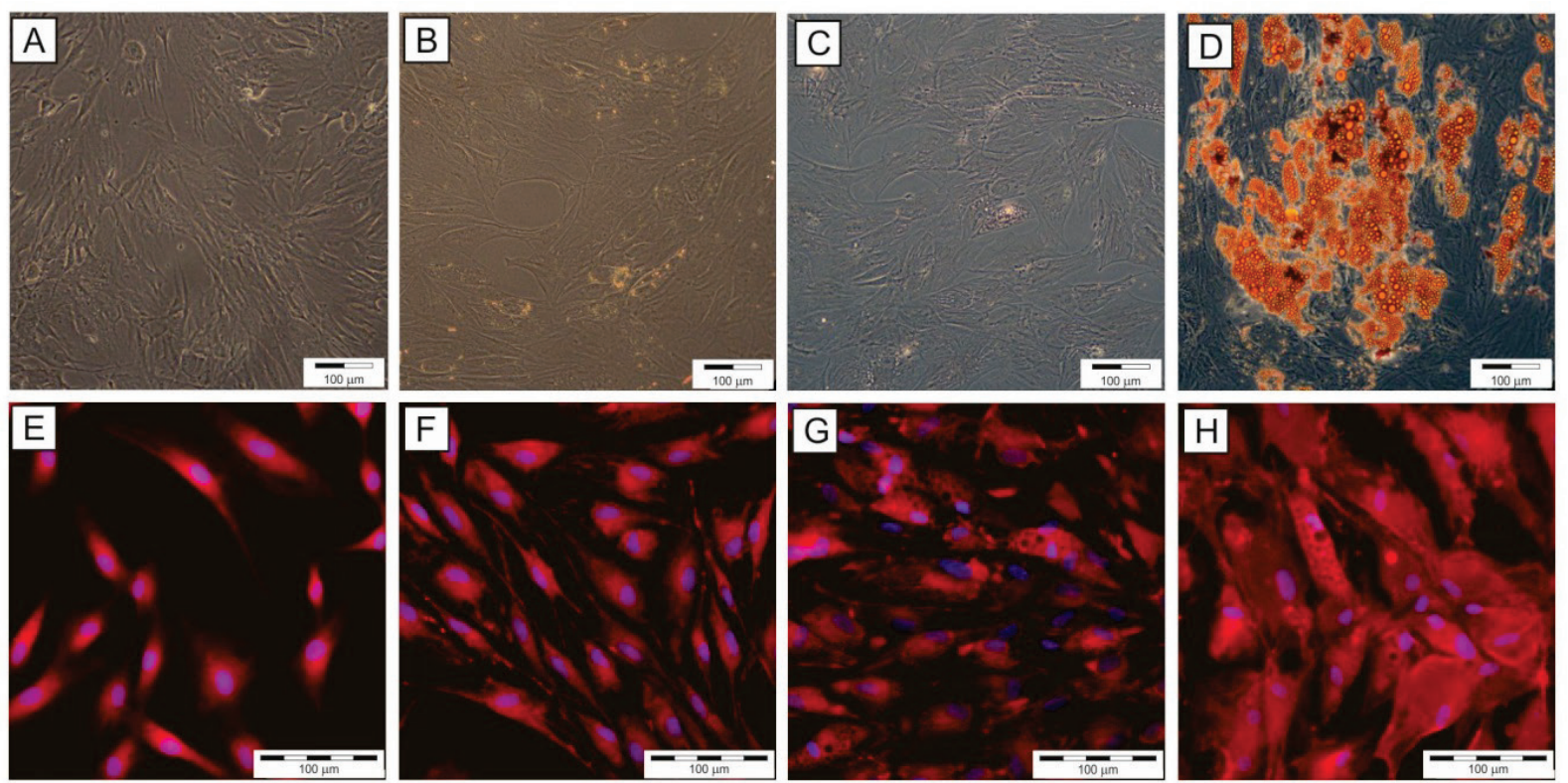

Fig. 1. Adipocyte differentiation (A-D) and mitochondria analysis using MitoTrackerTM (E-H). (A) Human adipose-derived mesenchymal stem cells stained with Oil Red O. (B-D) Adipocytes stained with Oil Red $O$ on days 4, 10, and 21 of differentiation. (E) Mitochondria in human adipose-derived mesenchymal stem cells stained using MitoTrackerTM. (F-H) Mitochondria in adipocytes on days 4,10 , and 21 of differentiation stained by MitoTrackerTM.

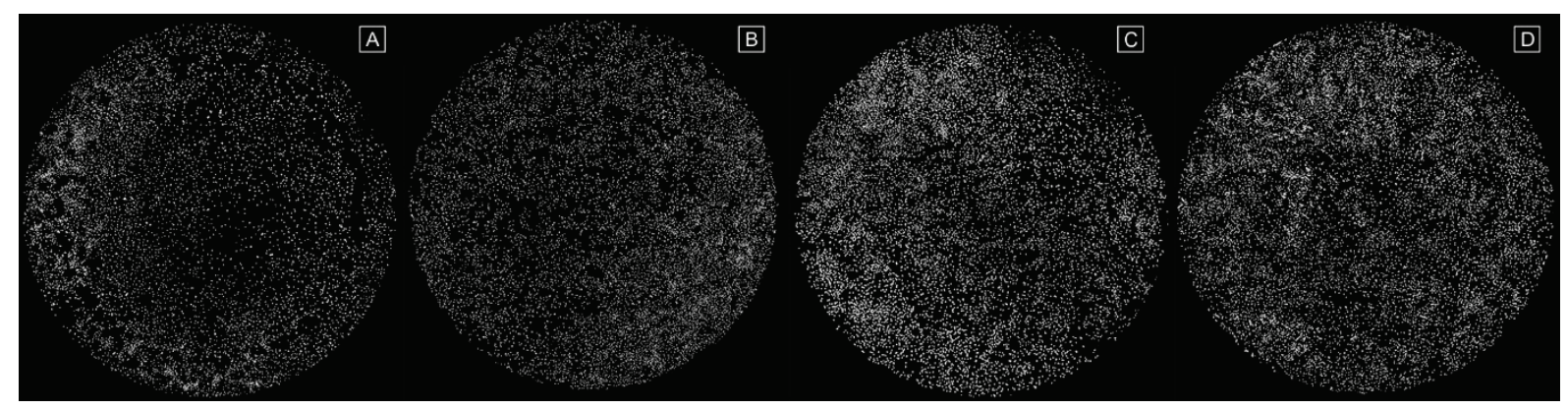

Fig. 2. Quantification of the number of cell nuclei (NucBlue $($ ) in the course of adipocyte differentiation from human adipose-derived mesenchymal stem cells on days $0(\mathbf{A}), 4(\mathbf{B}), 10$ (C), and 21 (D).

A

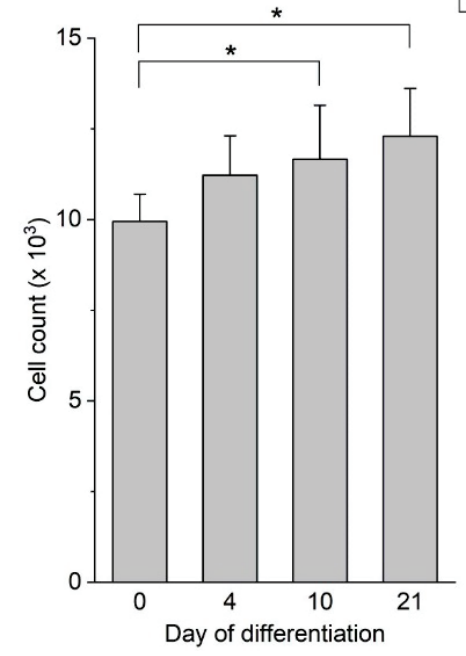

B

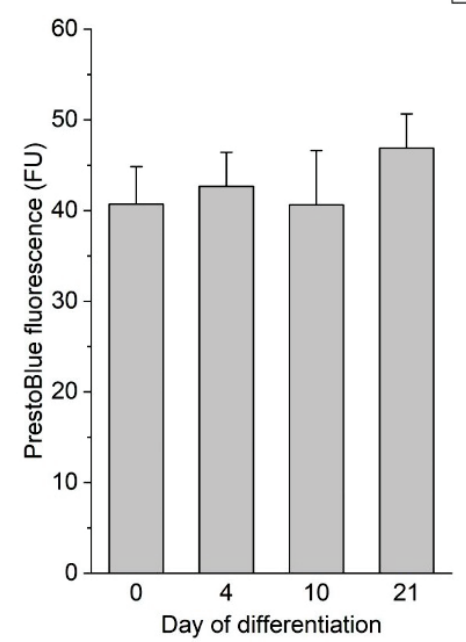

C

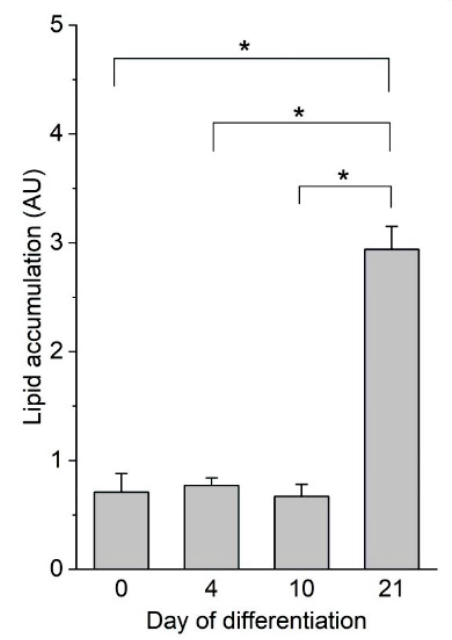

Fig. 3. (A) Proliferation (NucBlue $\Re$ ), (B) cell viability (PrestoBlueTM), and (C) lipid accumulation (Oil Red 0 ) in adipocytes differentiating from human adipose-derived mesenchymal stem cells on days $0,4,10$, and 21 of differentiation. 


\section{Qualitative and quantitative analysis of mitochondria}

Fluorescence microscopy showed that during the adipocyte differentiation, the volume of mitochondrial networks apparently increased (Fig. 1E-H). These data corresponded with the results of determination of the citrate synthase activity. At the end of the differentiation, citrate synthase activity was $92.7 \pm 33.5 \mathrm{mIU} / 10^{6}$ cells and it was significantly higher than on day 4 $\left(17.9 \pm 4.5 \mathrm{mIU} / 10^{6}\right.$ cells $)$ and day $0 \quad(19.3 \pm 0.8 \mathrm{mIU} /$ $10^{6}$ cells). The data suggest increasing mitochondrial quantity during differentiation.

\section{High-resolution respirometry}

As shown in Figure 4B-D, respirometric parameters have significantly changed in the course of adipogenesis. Basic respirometric states, i.e. R, L and E progressively increased in the course of differentiation (Fig. 4B). Interestingly, the most abrupt change of the state LEAK was observed between days 4 and 21 . ATP-related oxygen consumption (R-L) and excess ETS capacity (E-R) increased significantly between days 0 and 4 and then they did not substantially change (Fig. 4C). LEAK control ratio, expressed as L/E was not different between days 0 and 4 of adipocyte differentiation and then it significantly increased on day 21 . NetROUTINE control ratio expressing oxygen consumption related to ATP production (R-L) as a fraction of ETS capacity $((\mathrm{R}-\mathrm{L}) / \mathrm{E})$ increased between days 0 and 4 of the cell differentiation and then remained constant (Fig. 4D).
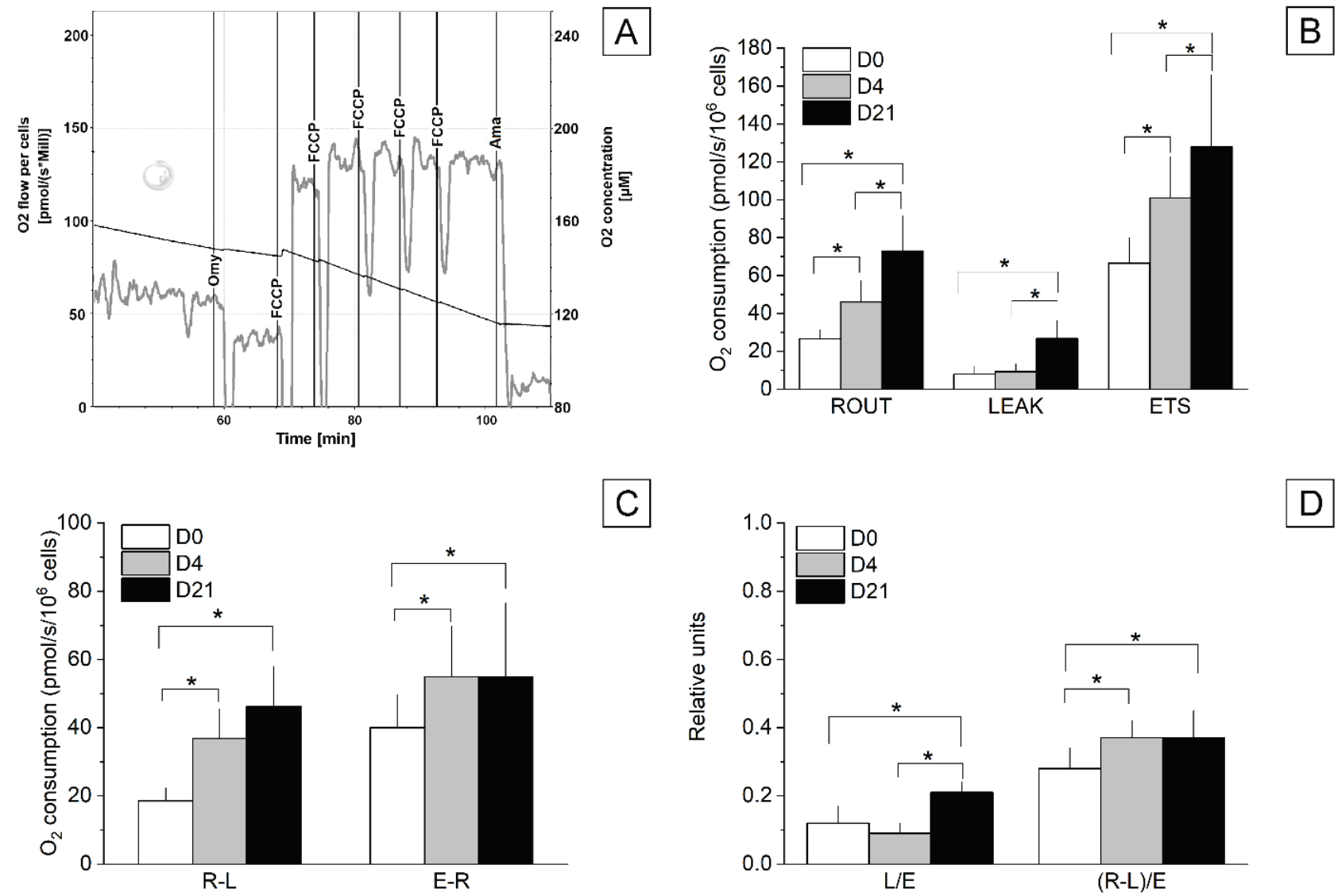

Fig. 4. Mitochondrial respiration in differentiating adipocytes on days 0,10 , and 21 of adipogenesis. (A) Titration protocol in adipocytes on day 21 of differentiation. Grey line=oxygen flux expressed in pmol/s per $10^{6}$ cells. Black line=concentration of oxygen in the oxygraph chamber $(\mu \mathrm{mol} / \mathrm{l})$. Omy=oligomycin, FCCP=trifluorocarbonylcyanide phenylhydrazone, Ama=antimycin A. (B) Routine (R), LEAK (L), and uncoupled (E) oxygen consumption after addition of cells, Omy, and FCCP, respectively, after correction to residual oxygen consumption after Ama. (C) ATP-related oxygen consumption (R-L) and excess ETS capacity (E-R). (D) Flux control ratios documenting coupling state (L/E) and NetROUTINE control ratio ((R-L)/E). Significant differences $p<0.05\left(^{*}\right)$.

\section{Mitochondrial membrane potential}

JC-1 dye is widely used to monitor mitochondrial health by measuring mitochondrial membrane potential. The low mitochondrial membrane potential is characterized by green fluorescence while high membrane potential is red. Consequently, mitochondrial depolarization is indicated by a decrease in the red/green fluorescence intensity ratio. We observed 
a decrease of this ratio during differentiation of hADMSCs to adipocytes by spectrophotometer assay (ratio 1.55 and 0.24 on days 4 and 21 , respectively). The same trend was confirmed by flow cytometry (the ratio 3.19 on day 4 and 2.33 on day 21). The decrease of red fluorescence during differentiation is a signal of the mitochondrial depolarization and this trend fully corresponds to the results of high-resolution respirometry.

\section{Discussion}

The present study describes the increasing cellular oxygen consumption during 21-day adipogenic differentiation of human adipose-derived mesenchymal stem cells. It is well known that stem cells are highly glycolytic cells and have mechanisms that actively suppress mitochondrial respiration (Khacho and Slack 2017). Stem cells are probably less dependent on functional mitochondria for energy or metabolic needs but upon initiation of and during differentiation, a metabolic switch towards oxidative phosphorylation is necessary to get enough energy. This change must be logically accompanied by mitochondrial biogenesis. It appears that mitochondrial biogenesis and increased mitochondrial respiration is likely a general hallmark of adult stem cell differentiation (Hofmann et al. 2012, Zhang et al. 2013, Tang and Lane 2012).

Adipogenic differentiation of hADMSCs was induced using commercial culture medium and after four days, we observed very tiny lipid droplets. In differentiating cells, the number and size of lipid droplets increased the most abruptly between days 10 and 21 and this trend was documented by Oil Red $\mathrm{O}$ staining. The viability test quantifying reduction of the non-fluorescent resazurin to the fluorescent resorufin by the mitochondrial and cytoplasmic enzymes indicated that there was no trend to impaired cellular metabolism during adipocyte differentiation (Zalata et al. 1998).

All parameters associated with the potential ability of the cells to increase oxygen consumption, i.e. basic respirometric states, excess E-R capacity and ATP-related oxygen consumption (R-L) were significantly higher at the end of differentiation. Interestingly, the most abrupt changes of the state R-L and E-R were observed between days 0 and 4 and then they did not substantially change. This could be related to the fact that during the first four days of differentiation, the cells are able to divide and grow and their metabolic needs are increased. The amount of mitochondria increased the most between days 4 and 10/21 suggesting that the transition from glycolytic to oxidative metabolism energy is very fast but for the change of cell phenotype more time is required (Drehmer et al. 2016, Tang and Lane 2012).

Mitochondrial uncoupling during differentiation led to mitochondrial membrane depolarization and as a result, increased LEAK oxygen consumption needed for compensation for the proton leak. This would lead to substantial suppression of ATP generation (Bouillaud et al. 1984). However, in the cells undergoing adipogenesis, state ROUTINE continuously increased maintaining capacity to produce ATP sufficient for the metabolic needs, e.g. fatty acid synthesis (Zhang et al. 2013). Excess E-R capacity reflecting the maximum ability of mitochondria to enhance electron transport, increased only between days 0 and 4 of adipocyte differentiation and then it remained constant implying that after day 4 , routine respiration could be increased only on the account of total electron-transporting capacity of mitochondria. High LEAK state and L/E uncoupling ratio on day 21 of adipogenesis could be related to increased expression of the uncoupling proteins UCP1, UCP2 and UCP3, which are responsible for disconnection between oxygen consumption and ATP production (Zhang et al. 2013). Another factor contributing to the increased LEAK state in the later stages of adipocyte differentiation could be activation of the mitochondrial permeability transition pore induced by long exposure to dexamethasone, regular component of media used for adipogenic differentiation (Chen et al. 2016, Luan et al. 2019).

In addition, parameters quantifying amount of mitochondrial mass fully corresponded with the above mentioned statements. The volume of mitochondrial networks and citrate synthase activity, marker of mitochondrial content (Larsen et al. 2012) increased during differentiation. Moreover, perinuclear localization of mitochondria was typical for undifferentiated cells, whereas mitochondria of mature adipocytes were more evenly distributed in the cytoplasm, especially around the lipid vacuoles. This observation was in accord with the study of Hofmann et al. (2012) and it supports the theory that the changes in distribution of mitochondria network could be a marker of successful differentiation of hADMSCs.

In summary, we showed that adipogenic differentiation of hADMSCs is a complex phenomenon 
regulated on multiple levels and it is accompanied by changes of the mitochondrial phenotype. It suggests that mitochondrial metabolism should not be considered as a consequence of differentiation but a key mechanism in this process. Regulation of mitochondrial respiration may be an important therapeutic approach that could be explored as a new target to treat obesity-related disorders. Unlike the previous studies, our work provides an assessment of mitochondrial oxygen consumption by cells in the course of complete 21-day lasting adipogenesis and uses for the differentiation stem cells derived from human adipose tissue.

\section{Study limitations}

In this study, we have used human adiposederived stem cells to determine basic mitochondrial characteristics in the course of their differentiation into mature adipocytes. Unlike commonly used human bone marrow mesenchymal cells (Charbord 2010) they enable less invasive recovery from patients while maintaining the same phenotype and functional characteristics. However, full adipogenesis is time-consuming and expensive process associated with many technical problems, like increasing fragility of the cells and their difficult harvesting. Although expression of FABP4 confirmed successful differentiation and maturation of adipocytes (Baxa et al. 1989), final cells did not contain a single lipid droplet typical for mature cells of white adipose tissue, but rather multiple lipid droplets resembling fat stores in the brite/beige adipocytes (Cedikova et al. 2016). In addition, mature cells loose viability early after the end of differentiation, which makes experiments with chronic exposure of these adipocytes to potentially harmful chemicals impossible. Nevertheless, they represent an excellent tool in research of adipogenesis from its very beginning (i.e. from the commitment of adipose-derived stem cells) in humans.

\section{Conflict of Interest}

There is no conflict of interest.

\section{Acknowledgements}

The study was supported by the project No. CZ.02.1.01/0.0/0.0/17_048/0007267, "Research and Development of Intelligent Components of Advanced Technologies for the Pilsen Metropolitan Area (InteCom)", awarded by the MEYS CR, financed from ERDF CZ, project No. CZ.02.1.01/0.0/0.0/16_019/ 0000787 "Fighting INfectious Diseases", awarded by the MEYS CR, financed from EFRR, Charles University Research Fund (Progres Q39), by the National Sustainability Program I (NPUI) Nr. LO1503 provided by the MEYS CR, and the Specific Student Research Project No. 260394/2017 of the Charles University in Prague.

\section{References}

BAXA CA, SHA RS, BUELT MK, SMITH AJ, MATARESE V, CHINANDER LL, BOUNDY KL, BERNLOHR DA: Human adipocyte lipid-binding protein: purification of the protein and cloning of its complementary DNA. Biochemistry 28: 8683-8690, 1989.

BERRY R, JEFFREY E, RODEHEFFER MS: Weighing in on adipocyte precursors. Cell Metab 19: 8-20, 2014.

BOUILLAUD F, RICQUIER D, MORY G, THIBAULT J: Increased level of mRNA for the uncoupling protein in brown adipose tissue of rats during thermogenesis induced by cold exposure or norepinephrine infusion. J Biol Chem 259: 11583-11586, 1984.

CAI L, LUBITZ J, FLEGAL KM, PAMUK ER: The predicted effects of chronic obesity in middle age on medicare costs and mortality. Med Care 48: 510-517, 2010.

CASTRO AVB, KOLKA CM, KIM SP, BERGMAN RN: Obesity, insulin resistance and comorbidities? Mechanisms of association. Arq Bras Endocrinol Metabol 58: 600-609, 2014.

CEDIKOVA M, KRIPNEROVA M, DVORAKOVA J, PITUlE P, GRUNDMANOVA M, BABUSKA V, MULLEROVA D, KUNCOVA J: Mitochondria in white, brown, and beige adipocytes. Stem Cells Int 2016: $6067349,2016$.

CHARBORD P: Bone marrow mesenchymal stem cells: historical overview and concepts. Hum Gene Ther 21: 1045-1056, 2010. 
CHEN Q, SHOU P, ZHENG C, JIANG M, CAO G, YANG Q, CAO J, XIE N, VELLETRI T, ZHANG X, XU C, ZHANG L, YANG H, HOU J, WANG Y, SHI Y: Fate decision of mesenchymal stem cells: adipocytes or osteoblasts? Cell Death Differ 23: 1128-1139, 2016.

DEJMEK J, KOHOUTOVA M, KRIPNEROVA M, CEDIKOVA M, TUMA Z, BABUSKA V, BOLEK L, KUNCOVA J: Repeated exposure to hyperbaric hyperoxia affects mitochondrial functions of the lung fibroblasts. Physiol Res 67 (Suppl 4): S633-S643, 2018.

DREHMER DL, DE AGUIAR AM, BRANDT AP, PETIZ L, CADENA SM, REBELATTO CK, BROFMAN PR, FILIPAK NETO F, DALLAGIOVANNA B, ABUD AP: Metabolic switches during the first steps of adipogenic stem cells differentiation. Stem Cell Res 17: 413-421, 2016.

HOFMANN AD, BEYER M, KRAUSE-BUCHHOLZ U, WOBUS M, BORNHAUSER M, RODEL G: OXPHOS supercomplexes as a hallmark of the mitochondrial phenotype of adipogenic differentiated human MSCs. PLoS One 7: e35160, 2012.

KHACHO M, SLACK RS: Mitochondrial activity in the regulation of stem cell self-renewal and differentiation. Curr Opin Cell Biol 49: 1-8, 2017.

KUSMINSKI CM, SCHERER PE: Mitochondrial dysfunction in white adipose tissue. Trends Endocrinol Metab 23: 435-443, 2012.

KUZNETSOV AV, STROBL D, RUTTMANN E, KONIGSRAINER A, MARGREITER R, GNAIGER E: Evaluation of mitochondrial respiratory function in small biopsies of liver. Anal Biochem 305: 186-194, 2002.

LARSEN S, NIELSEN J, HANSEN CN, NIELSEN LB, WIBRAND F, STRIDE N, SCHRODER HD, BOUSHEL R, HELGE JW, DELA F, HEY-MORGENSEN M: Biomarkers of mitochondrial content in skeletal muscle of healthy young human subjects. J Physiol (Lond) 590: 3349-3360, 2012.

LUAN G, LI G, MA X, JIN Y, HU N, LI J, WANG Z, WANG H: Dexamethasone-induced mitochondrial dysfunction and insulin resistance-study in 3T3-L1 adipocytes and mitochondria isolated from mouse liver. Molecules 24: E1982, 2019.

LUNA-LUNA M, MEDINA-URRUTIA A, VARGAS-ALARCON G, COSS-ROVIROSA F, VARGAS-BARRON J, PEREZ-MENDEZ O: Adipose tissue in metabolic syndrome: onset and progression of atherosclerosis. Arch Med Res 46: 392-407, 2015.

LUZ AL, KASSOTIS CD, STAPLETON HM, MEYER JN: The high-production volume fungicide pyraclostrobin induces triglyceride accumulation associated with mitochondrial dysfunction, and promotes adipocyte differentiation independent of PPAR $\gamma$ activation, in 3T3-L1 cells. Toxicology 393: 150-159, 2018.

MISSION JF, MARSHALL NE, CAUGHEY AB: Pregnancy risks associated with obesity. Obstet Gynecol Clin North Am 42: 335-353, 2015.

MORRISON S, MCGEE SL: 3T3-L1 adipocytes display phenotypic characteristics of multiple adipocyte lineages. Adipocyte 4: 295-302, 2015.

MULLEROVA D, PESTA M, DVORAKOVA J, CEDIKOVA M, KULDA V, DVORAK P, BOUCHALOVA V, KRALICKOVA M, BABUSKA V, KUNCOVA J, LANGMAJEROVA J, MULLER L: Polychlorinated biphenyl 153 in lipid medium modulates differentiation of human adipocytes. Physiol Res 66: 653-662, 2017.

PESTA D, GNAIGER E: High-resolution respirometry: OXPHOS protocols for human cells and permeabilized fibers from small biopsies of human muscle. Methods Mol Biol 810: 25-58, 2012.

QIAO L, CHU K, WATTEZ JS, LEE S, GAO H, FENG GS, HAY WW, SHAO J: High-fat feeding reprograms maternal energy metabolism and induces long-term postpartum obesity in mice. Int $J$ Obes (Lond) 43: 1747-1758, 2019.

SADIE-VAN GH: Adipocyte biology: It is time to upgrade to a new model. J Cell Physiol 234: 2399-2425, 2019.

SHEPHERD PR, GNUDI L, TOZZO E, YANG H, LEACH F, KAHN BB: Adipose cell hyperplasia and enhanced glucose disposal in transgenic mice overexpressing GLUT4 selectively in adipose tissue. J Biol Chem 268: 22243-22246, 1993.

SPIEGELMAN BM, FLIER JS: Adipogenesis and obesity: rounding out the big picture. Cell 87: 377-389, 1996.

TANG QQ, LANE MD: Adipogenesis: from stem cell to adipocyte. Annu Rev Biochem 81: 715-736, 2012. 
ZALATA AA, LAMMERTIJN N, CHRISTOPHE A, COMHAIRE FH: The correlates and alleged biochemical background of the resazurin reduction test in semen. Int J Androl 21: 289-294, 1998.

ZHANG Y, MARSBOOM G, TOTH PT, REHMAN J: Mitochondrial respiration regulates adipogenic differentiation of human mesenchymal stem cells. PLoS One 8: e77077, 2013.

ZIMMET P, ALBERTI KG, SHAW J: Global and societal implications of the diabetes epidemic. Nature 414: 782-787, 2001. 